\title{
COMUNICAÇÃO
}

\section{LEVANTAMENTO ETNOBOTÂNICO E CARACTERIZAÇÃo DE PLANTAS MEDICINAIS EM FRAGMENTOS FLORESTAIS DE DOURADOS-MS}

\author{
Etnobotanical survey and medicinal plants characterization in forest fragments in Dourados-MS
}

\author{
Elma Oliveira Alves ${ }^{1}$ José Hortêncio Mota ${ }^{2}$, Thelma Shirlen Soares ${ }^{3}$, \\ Maria do Carmo Vieira ${ }^{4}$, Cristiane Bezerra da Silva ${ }^{5}$
}

\begin{abstract}
RESUMO
Objetivou-se, neste estudo, coletar e identificar espécies nativas consideradas medicinais em dois fragmentos florestais no município de Dourados-MS. Foram identificadas 37 espécies distribuídas em 28 famílias as quais foram indicadas pelos mateiros da região por serem utilizadas pela população como alternativa medicinal. Das famílias identificadas, as que apresentaram maior número de espécies foram Piperaceae (10,8\%), Moraceae (8,1\%), Smilaceae (8,1\%), Myrtaceae $(5,4 \%)$ e Rubiacee $(5,4 \%)$. O levantamento etnobotânico indicou 45 diferentes usos medicinais para as espécies e as partes mais utilizadas para o preparo de remédios são as folhas e cascas, sendo que as doenças para as quais houve maior número de indicações foram reumatismo, disenteria, diabetes, febres, tosses e cicatrizações.
\end{abstract}

Termos para indexação: Espécies nativas, medicina popular, conhecimento popular.

\section{ABSTRACT}

The objective of this study was to collect and to identify native species considered medicinal in forest fragments in DouradosMato Grosso Sul. Had been identified 37 species distributed in 28 families which had been indicated by the woodsman of the region for being used by the population as medicinal alternative. Families that presented greater number of species were Piperaceae (10.8\%), Moraceae (8.1\%), Smilaceae (8.1\%), Myrtaceae (5.4\%) and Rubiacee (5.4\%). The etnobotanical survey indicated 45 different medicinal uses for the species, the used parts more for the preparation of remedies is the leaves and bark, being that the illnesses for which bigger number of indications had been rheumatism, dysentery, diabetes, fevers, coughs and cicatrizations.

Index terms: Native species, popular medicine, popular knowledge.

(Recebido em 5 de dezembro de 2006 e aprovado em 25 de junho de 2007)

O Brasil destaca-se por ser o país com maior biodiversidade mundial possuindo, de acordo com Marques (2000), 22\% de todas as espécies biológicas do mundo. Dentro desse leque único de riquezas biológicas, o país também se destaca em outro aspecto no que diz respeito às plantas: as florestas brasileiras guardam um número significativo de espécies que têm fins terapêuticos e medicinais. O Brasil possui um imenso potencial genético a ser explorado e estima-se que esse patrimônio vegetal represente cerca de 16,5 bilhões de genes (RAMOS, 2000).

Em sua complexa biodiversidade, existe um grande número de plantas que são utilizadas pelas populações para o tratamento de diversas enfermidades, tanto para seres humanos quanto para animais domésticos (MING, 1995). Segundo Elisabetsky \& Setzer (1987), a coleta de informações dessas populações também é fundamental para se obter e resgatar o conteúdo de aspectos culturais, muitas vezes específicos de cada local e importantes para o uso coerente das plantas.

Entretanto, devido à expansão das fronteiras agrícolas e urbanas, a flora medicinal brasileira, aos poucos, tem sido modificada quanto à sua fisionomia e habitat $\mathrm{e}$, em consequiência, algumas espécies tornam-se cada vez mais raras em razão da coleta indiscriminada e sem controle por mateiros, raizeiros e comunidades locais (SÓ..., 2000). Todos esses impactos na flora trazem uma redução

\footnotetext{
${ }^{1}$ Graduanda em Ciências Biológicas - Faculdade de Ciências Biológicas/FCB - Universidade Federal da Grande Dourados/UFGD - Cx. Postal 533 79804-970 - Dourados, MS - elmabio@gmail.com

${ }^{2}$ Engenheiro Agrônomo, Doutor, Professor - Centro Federal de Educação Tecnológica de Cuiabá - BR 364, Km 329 - São Vicente da Serra - $78106-970$ Santo Antônio do Leverger, MT - hortenciomota@terra.com.br

${ }^{3}$ Engenheira Florestal, Doutora, Professora - Faculdade de Engenharia Florestal/FENF - Universidade Federal de Mato Grosso/UFMT - Avenida Fernando Correa da Costa, s/n, Boa Esperança - 78060-900 - Cuiabá, MT - thelsoares@ufmt.br

${ }^{4}$ Engenheira Agrônoma, Doutora, Professora - Faculdade de Ciências Agrárias/FCA - Universidade Federal da Grande Dourados/UFGD - Cx. Postal 533 - 79804-970 - Dourados, MS - vieiracm@terra.com.br

${ }^{5}$ Bióloga, Mestranda em Biologia Vegetal - Departamento de Biologia/DBI - Universidade Federal de Mato Grosso do Sul/UFMS - Cx. P. 549 - 79070 900 - Campo Grande, MS - cris.mpj@gmail.com
} 
expressiva das espécies vegetais consideradas medicinais, antes mesmo de serem estudadas.

De acordo com Rodrigues (1998), tendo em vista a importância de sanar, ou pelo menos de amenizar os problemas socioeconômicos da população brasileira, é crescente a preocupação em se estabelecer espécies de plantas medicinais para pesquisas, suas potencialidades, usos e meios de conservação desses recursos genéticos

Na região sul do Estado do Mato Grosso do Sul, estudos que evidenciam a ocorrência de espécies utilizadas na medicina popular ainda são escassos; citam-se os estudos realizados por Sangalli \& Vieira (2003) e Sangalli et al. (2002), sendo que muitos aspectos da flora medicina nessa região ainda permanecem desconhecidos.

Nesse contexto, a investigação etnobotânica pode desempenhar funções de grande importância, como reunir informações acerca de todos os possíveis usos das plantas, contribuindo para o desenvolvimento de novas formas de exploração dos ecossistemas que se oponham às formas destrutivas vigentes (CABALLERO, 1983).

Objetivou-se, neste estudo, realizar um levantamento etnobotânico das espécies vegetais, com propriedades medicinais, em dois fragmentos florestais localizados no município de Dourados-MS.

$\mathrm{O}$ estudo foi realizado em dois fragmentos de mata nativa localizados no município de Dourados, Estado de Mato Grosso do Sul, entre os paralelos $21^{\circ} 50^{\prime}$ e $22^{\circ} 24^{\prime}$ de latitude sul e os meridianos 54 $14^{\circ}$ ' e $55^{\circ} 33^{\prime}$ de latitude oeste de Greenwich, com altitude média de $430 \mathrm{~m}$.

O clima da região é do tipo mesotérmico de inverno seco e moderadamente frio, e verão quente e chuvoso (Cwa de Köppen), caracterizado por apresentar temperatura média anual de $22^{\circ} \mathrm{C}$. A precipitação pluviométrica média anual é de 1400 mm e a evapotranspiração anual é de 1100 a $1200 \mathrm{~mm}$ (ALVES SOBRINHO et al., 1998).

As áreas estudadas (Figura 1) pertencem respectivamente às Fazendas Ouro Verde e Moeda que, tradicionalmente, são produtoras de grãos. Ambas as áreas caracterizam-se como áreas de vegetação classificadas como floresta estacional semidecídua, de acordo com o sistema de classificação do Instituto Brasileiro de Geografia e Estatística - IBGE (VELOSO et al., 1991).

A Fazenda Ouro Verde localiza-se à direita da BR 267 sentido Dourados - Campo Grande sendo que o fragmento de vegetação nativa estudado possui uma área de 62,3 ha e está localizado a uma altitude média de $417 \mathrm{~m}$. A Fazenda Moeda está localizada na Estrada de Porto Cambira, à esquerda da BR 267, sentido Dourados - Ponta Porã, e a área estudada está localizada a uma altitude média de $336 \mathrm{~m}$ e possui 18,3 ha.

O levantamento das espécies medicinais foi realizado por meio de coletas aleatórias, em toda a área, dos fragmentos, isso foi feito por caminhamento sistemático acompanhado por mateiros da região. O levantamento etnobotânico contou com o conhecimento tradicional dos mateiros da região, que acompanharam as coletas, por causa da sua grande experiência na identificação das plantas e também como forma de resgatar as informações a respeito das plantas nativas com propriedades medicinais, auxiliando na identificação das espécies e no registro do uso medicinal das mesmas.

Das espécies relatadas como medicinais foram coletados ramos das plantas com flores, além das partes indicadas como medicinais, como folhas, cascas ou

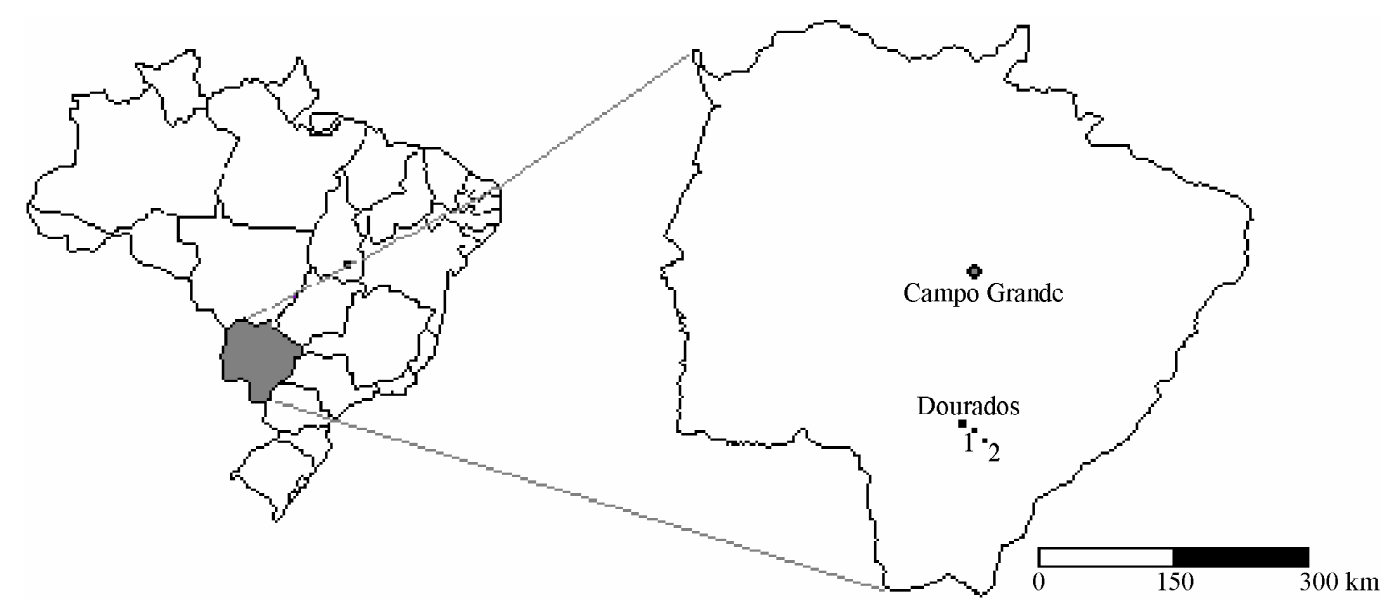

Figura 1 - Localização dos fragmentos estudados em relação à sede do município de Dourados-MS, em que: 1 = Fazenda Ouro Verde e 2 = Fazenda Moeda. 
sementes. As plantas coletadas foram herborizadas e as amostras estão depositadas no herbário da UFGD.

As identificações botânicas foram feitas por meio de comparações com exsicatas depositadas nos Herbários de Dourados (Herbário DDMS - Dourados-MS) e da UFMS (Herbário CG-MS - Campo Grande-MS) e, também, por consultas a especialistas e obras clássicas.

Os nomes das espécies e seus autores foram confirmados e atualizados por bibliografia específica e também por meio do site do Missouri Botanical Garden (http://www.mobot.org/w3t/search/vast.html). O sistema de classificação adotado foi o APG II (APG, 2003).

O grau de ocorrência das espécies medicinais amostradas foi avaliado de acordo com a DAFOR (KENT \& COKER, 1992), que foi comparado com levantamentos etnobotânicos realizados em outros fragmentos nativos, no município de Dourados-MS (BRATTI et al., 2004; FORTES et al., 2004; QUEIROZ et al., 2005; SANGALLI et al., 2002; SANTOS et al., 2002; SILVA et al., 2004).

Foram identificadas, nos dois fragmentos florestais, 28 famílias e 37 espécies, consideradas medicinais, segundo o uso popular na região. Foram identificadas 26 espécies medicinais na Fazenda Ouro Verde, 8 espécies na Fazenda Moeda e 3 espécies comuns em ambas as áreas.

Das famílias catalogadas, as que apresentaram maior número de espécies foram Piperaceae $(10,8 \%)$, Moraceae $(8,1 \%)$, Smilacaceae $(8,1 \%)$, Myrtaceae $(5,4 \%)$ e Rubiacee $(5,4 \%)$, conforme apresenta-se na Figura 2. Os gêneros que apresentaram maior número de espécies foram Smilax (3) e Piper (2), sendo que os demais gêneros apresentaram apenas uma espécie cada.

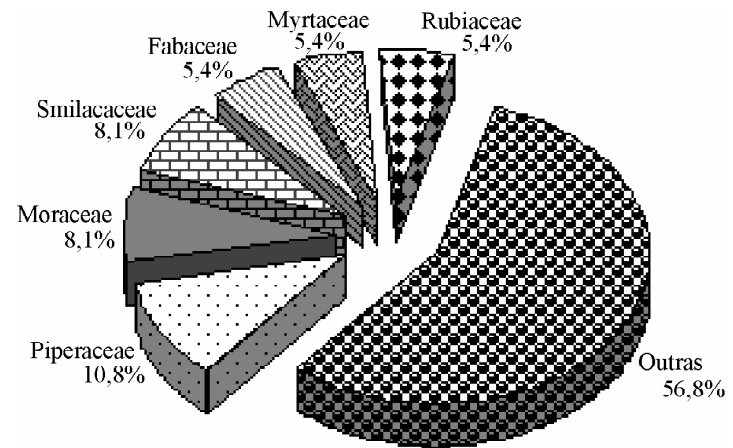

Figura 2 - Representatividade das famílias com maior número de espécies empregadas como medicinal pela população de Dourados-MS, nos fragmentos florestais estudados.

Com relação ao grau de ocorrência das espécies medicinais amostradas nos dois fragmentos e comparadas com outros levantamentos realizados, observou-se que $13,5 \%$ das espécies são abundantes, $43,3 \%$ freqüentes, $29,7 \%$ ocorrentes e $13,5 \%$ raras. Ressalte-se que as espécies relacionadas como de ocorrência rara foram encontradas apenas no levantamento realizado nas Fazendas Ouro Verde e Moeda e são elas: Astronium fraxinifolium Schott ex Spreng., Ficus guaranitica Chodat, Ilex paraguariensis A. St.-Hil., Inga sessilis (Vell.) Mart., com exceção Peperomia sp. que foi relatada, também, no levantamento etnobotânico realizado por Sangalli et al. (2002).

$\mathrm{Na}$ Tabela 1 listam-se as características das plantas catalogadas, coletadas e identificadas, de acordo com a classificação taxonômica (família, gênero e espécie), nome popular, local de ocorrência, indicações medicinais com base no saber da comunidade local.

A população da região, tradicionalmente, utiliza as plantas catalogadas para tratamento de diversas enfermidades, sendo que o conhecimento sobre as espécies e formas de utilização é aprendida e repassada de geração para geração.

Dessas espécies, as partes mais utilizadas para o preparo de remédios são as folhas e cascas e também o emprego de raízes, caules, sementes, frutos e seiva (Figura 3). As folhas são tradicionalmente as partes mais utilizadas para tratamento medicinal popular, provavelmente por causa da facilidade de coleta e por estar presente na planta, durante a maior parte do ano.

De acordo com as indicações medicinais populares, as enfermidades para as quais foram citadas mais plantas foram as seguintes: reumatismo (5), diurético (4), dores na coluna (4), problemas renais (4), calmante (3), depurativo do sangue (3), disenteria (3), dores no fígado (3), febre (3), anti-séptico (2), cicatrizante (2), diabetes (2), doenças do baço (2), doenças venéreas (2), gripe (2), má-digestão (2), malária (2). Observou-se, também, que uma mesma planta é usada para debelar diferentes patologias.

Muitas das espécies coletadas foram citadas em trabalhos realizados em outras localidades ou estados, como por exemplo, no estudo realizado por Bueno et al. (2005) das plantas medicinais usadas pelas populações indígenas Kaiowá e Guarani na Reserva de Caarapó em Mato Grosso do Sul no qual Eugenia uniflora L., Maclura tinctoria (L.) D. Don ex Steud., Psidium guajava L., Pothomorphe umbellata (L.) Miq. e Stachytarpheta cayennensis (Rich.) Vahl foram citadas. Fonseca-Kruel \& Peixoto (2004), em levantamento etnobotânico realizado na Reserva Extrativista Marinha de Arraial do Cabo, no Estado do Rio de Janeiro, relataram as espécies Eugenia uniflora L., Piper amalago L., Pothomorphe umbellata (L.) Miq., Trema micrantha (L.) Blume e Stachytarpheta cayennensis (Rich.) Vahl. 
Tabela 1 - Relação das espécies ocorrentes nas Fazendas Ouro Verde e Moeda e uso medicinal segundo o conhecimento popular da região Em que: Local 1 = Fazenda Ouro Verde; Local 2 = Fazenda Moeda).

\begin{tabular}{|c|c|c|c|}
\hline Nome científico & Nome vulgar & Local & Uso \\
\hline \multicolumn{4}{|l|}{ ANACARDIACEAE } \\
\hline $\begin{array}{l}\text { Astronium fraxinifolium Schott } \\
\text { ex Spreng. }\end{array}$ & gonçalo-alves & 1 & $\begin{array}{l}\text { Utiliza-se o chá da casca no combate a } \\
\text { doenças venéreas. }\end{array}$ \\
\hline \multicolumn{4}{|l|}{ AQUIFOLIACEAE } \\
\hline Ilex paraguariensis A. St.-Hil. & erva-mate & 1 & $\begin{array}{l}\text { O chá das folhas é usado no combate ao } \\
\text { derrame. }\end{array}$ \\
\hline \multicolumn{4}{|l|}{ ARISTOLOCHIACEAE } \\
\hline Aristolochia esperanzae Kuntze & $\begin{array}{l}\text { cipó-mil- } \\
\text { homens }\end{array}$ & 1 & $\begin{array}{l}\text { O chá do cipó (caule) e folhas é indicado } \\
\text { no tratamento de cólera, disenteria, } \\
\text { reumatismo, febre e malária. }\end{array}$ \\
\hline \multicolumn{4}{|l|}{ ASTERACEAE } \\
\hline $\begin{array}{l}\text { Chuquiraga tomentosa Spreng.) } \\
\text { Baker }\end{array}$ & $\begin{array}{l}\text { cipó-espinho- } \\
\text { de-agulha }\end{array}$ & 1 & $\begin{array}{l}\text { O chá das folhas e raízes é indicado para } \\
\text { dores na coluna, rim e reumatismo. }\end{array}$ \\
\hline \multicolumn{4}{|l|}{ BIGNONIACEAE } \\
\hline Amphilophium sp. & $\begin{array}{l}\text { cipó-cruz; } \\
\text { cainca }\end{array}$ & 1 & $\begin{array}{l}\text { O chá do cipó (caule) é indicado para dores } \\
\text { de coluna, reumatismo e artrite. }\end{array}$ \\
\hline \multicolumn{4}{|l|}{ CECROPIACEAE } \\
\hline Cecropia pachystachya Trécul & embaúba & 1 & $\begin{array}{l}\text { O chá das raízes e folhas é empregado para } \\
\text { tratamentos de inflamações renais. }\end{array}$ \\
\hline \multicolumn{4}{|l|}{ EUPHOBIACEAE } \\
\hline Croton urucurana Baill. & sangra-d’água & 2 & $\begin{array}{l}\text { O chá da casca é indicado para gastrites, } \\
\text { úlceras e dores nas costas. }\end{array}$ \\
\hline \multicolumn{4}{|l|}{$\begin{array}{l}\text { FABACEAE } \\
\text { CAESALPINOIDEAE }\end{array}$} \\
\hline $\begin{array}{l}\text { Cassia ferruginea (Schrader) } \\
\text { Schrader ex DC. }\end{array}$ & canafístula & 1 & $\begin{array}{l}\text { O chá das folhas é usado em forma de } \\
\text { bochechos para inflamações dos dentes e } \\
\text { das amídalas. }\end{array}$ \\
\hline \multicolumn{4}{|l|}{ FABACEAE MIMOSOIDEAE } \\
\hline Inga sessilis (Vell.) Mart. & ingá & 1 & $\begin{array}{l}\text { O chá da casca é utilizado como anti- } \\
\text { séptico bucal. }\end{array}$ \\
\hline \multicolumn{4}{|l|}{ LAURACEAE } \\
\hline $\begin{array}{l}\text { Nectandra megapotamica } \\
\text { (Spreng.) Mez }\end{array}$ & $\begin{array}{l}\text { canela-preta, } \\
\text { canela-miúda }\end{array}$ & 1 & $\begin{array}{l}\text { O chá da folha é usado como calmante e no } \\
\text { tratamento de tosses e gripes. Usa-se a } \\
\text { casca desfiada e aquecida para o } \\
\text { tratamento de furúnculos. }\end{array}$ \\
\hline \multicolumn{4}{|l|}{ LECYTHIDACEAE } \\
\hline $\begin{array}{l}\text { Cariniana estrellensis (Raddi) } \\
\text { Kuntze }\end{array}$ & jequitibá & 1 & $\begin{array}{l}\text { O chá da casca é utilizado como anti- } \\
\text { séptico e para tratamento de aftas. }\end{array}$ \\
\hline
\end{tabular}

Continua... 
Tabela 1 - Continuação...

\begin{tabular}{|c|c|c|c|}
\hline Nome científico & Nome vulgar & Local & Uso \\
\hline \multicolumn{4}{|l|}{ MELIACEAE } \\
\hline Cedrela fissilis Vell. & cedro & 1 & $\begin{array}{l}\text { A casca é utilizada na forma de infusão } \\
\text { para tratamento de cólica intestinal, dor de } \\
\text { barriga, febre e aftas. }\end{array}$ \\
\hline \multicolumn{4}{|l|}{ MORACEAE } \\
\hline Ficus guaranitica Chodat & $\begin{array}{l}\text { figueira-mata- } \\
\text { pau }\end{array}$ & 1 & $\begin{array}{l}\text { A seiva da planta é utilizada como } \\
\text { vermífuga. }\end{array}$ \\
\hline $\begin{array}{l}\text { Maclura tinctoria (L.) D. Don ex } \\
\text { Steud. }\end{array}$ & $\begin{array}{l}\text { amoreira-brava; } \\
\text { tajuva }\end{array}$ & 2 & $\begin{array}{l}\text { O chá da casca é empregado para combater } \\
\text { dores na coluna. }\end{array}$ \\
\hline $\begin{array}{l}\text { Sorocea bonplandii (Baill.) W.C. } \\
\text { Burger, Lanj. \& Wess. Bôer }\end{array}$ & cincho, soroco & 1 & $\begin{array}{l}\text { O chá das folhas é usado no combate a } \\
\text { hipertensão e no tratamento de doenças } \\
\text { venéreas. }\end{array}$ \\
\hline
\end{tabular}

\begin{tabular}{|c|c|c|c|}
\hline \multicolumn{4}{|l|}{ MYRTACEAE } \\
\hline Eugenia uniflora L. & pitanga & 1 e 2 & $\begin{array}{l}\text { O chá das folhas é empregado como } \\
\text { calmante e diurético. }\end{array}$ \\
\hline Psidium guajava L. & araçá & 1 & $\begin{array}{l}\text { O chá da casca, broto e folhas é indicado } \\
\text { para tratamento de disenterias e diabetes. }\end{array}$ \\
\hline \multicolumn{4}{|l|}{ PASSIFLORACEAE } \\
\hline Passiflora sp. & maracujina & 1 & $\begin{array}{l}\text { Utiliza-se a polpa do fruto, em forma de } \\
\text { suco, e o chá das folhas como calmante. }\end{array}$ \\
\hline \multicolumn{4}{|l|}{ PIPERACEAE } \\
\hline Peperomia sp. & $\begin{array}{l}\text { jaborandi- } \\
\text { anestesiol }\end{array}$ & 1 & $\begin{array}{l}\text { Chás das folhas e do caule são analgésicos } \\
\text { e anestésicos. }\end{array}$ \\
\hline Piper aduncum L. & falso-jaborandi & 1 & $\begin{array}{l}\text { O chá das folhas é utilizado como tônico e } \\
\text { para tratamentos de infecções hepáticas. }\end{array}$ \\
\hline Piper amalago L. & jaborandi & 2 & $\begin{array}{l}\text { O chá das folhas é empregado no } \\
\text { tratamento de queimaduras. }\end{array}$ \\
\hline $\begin{array}{l}\text { Pothomorphe umbellata (L.) } \\
\text { Miq. }\end{array}$ & $\begin{array}{l}\text { pariparoba, } \\
\text { tabeba, } \\
\text { malvaísco }\end{array}$ & 2 & $\begin{array}{l}\text { As folhas maceradas em água gelada são } \\
\text { utilizadas para má digestão e dores } \\
\text { hepáticas. }\end{array}$ \\
\hline \multicolumn{4}{|l|}{ POACEAE } \\
\hline Olyra caudata Trin. & $\begin{array}{l}\text { taquarinha, } \\
\text { taboquinha }\end{array}$ & 1 e 2 & $\begin{array}{l}\text { Utiliza-se o chá das raízes para o } \\
\text { tratamento de doenças do baço e vesícula }\end{array}$ \\
\hline \multicolumn{4}{|l|}{ RUBIACEAE } \\
\hline Coffea arabica L. & café & 1 & $\begin{array}{l}\text { O banho utilizando as folhas é empregado } \\
\text { no combate ao remautismo e o chá das } \\
\text { sementes cruas empregado para diabetes. }\end{array}$ \\
\hline Genipa americana $\mathrm{L}$. & jenipapo & 1 e 2 & $\begin{array}{l}\text { Utiliza-se o chá da casca e das folhas como } \\
\text { depurativo do sangue. }\end{array}$ \\
\hline
\end{tabular}


Tabela 1 - Continuação...

\begin{tabular}{|c|c|c|c|}
\hline Nome científico & Nome vulgar & Local & Uso \\
\hline SAPINDACEAE & & & \\
\hline $\begin{array}{l}\text { Allophylus edulis (A. St.-Hil., } \\
\text { Cambess. \& A. Juss.) Radlk. }\end{array}$ & $\begin{array}{l}\text { cocum, vacum, } \\
\text { aperta-guela }\end{array}$ & 2 & $\begin{array}{l}\text { O chá das folhas é indicado para } \\
\text { tratamento de problemas hepáticos e } \\
\text { disenteria. }\end{array}$ \\
\hline
\end{tabular}

\section{SIPARUNACEAE}

Siparuna guianensis Aubl.

negramina

O banho utilizando as folhas é empregado no tratamento de dores musculares.

\begin{tabular}{|c|c|c|c|}
\hline \multicolumn{4}{|l|}{ SMILACACEAE } \\
\hline Smilax fluminensis Steud. & $\begin{array}{l}\text { japecanga- } \\
\text { graúda }\end{array}$ & 2 & $\begin{array}{l}\text { O chá das folhas é empregado como } \\
\text { depurativo do sangue. }\end{array}$ \\
\hline Smilax brasiliensis Spreng. & $\begin{array}{l}\text { japecanga- } \\
\text { miúda, } \\
\text { japecanga }\end{array}$ & 1 & $\begin{array}{l}\text { O chá das folhas é utilizado como diurético } \\
\text { e no tratamento de reumatismos. }\end{array}$ \\
\hline Smilax campestris Griseb. & $\begin{array}{l}\text { japecanga- } \\
\text { brava, salsa-do- } \\
\text { campo }\end{array}$ & 1 & $\begin{array}{l}\text { O chá das raízes é indicado para o } \\
\text { tratamento renais e como depurativo do } \\
\text { sangue. }\end{array}$ \\
\hline \multicolumn{4}{|l|}{ SOLANACEAE } \\
\hline Solanum viarum Dun & juá, juá-bravo & 2 & $\begin{array}{l}\text { As sementes assadas são utilizadas } \\
\text { externamente como cicatrizante. }\end{array}$ \\
\hline \multicolumn{4}{|l|}{ STERCULIACEAE } \\
\hline Guazuma ulmifolia Lam. & chico-magro & 1 & $\begin{array}{l}\text { O chá da casca é empregado como } \\
\text { diurético e emagrecedor. }\end{array}$ \\
\hline \multicolumn{4}{|l|}{ TEOPHRASTRACEAE } \\
\hline Clavija nutans (Vell.) B. Ståhl & $\begin{array}{l}\text { chá-de-bugre, } \\
\text { porangaba }\end{array}$ & 1 & $\begin{array}{l}\text { Chás das folhas são indicados para } \\
\text { tratamentos renais. }\end{array}$ \\
\hline \multicolumn{4}{|l|}{ ULMACEAE } \\
\hline Trema micrantha $(\mathrm{L}$.$) Blume$ & $\begin{array}{l}\text { candiúba, } \\
\text { periquiteira }\end{array}$ & 1 & $\begin{array}{l}\text { Folhas e cascas são utilizadas em chás } \\
\text { indicados no combate à sífilis e } \\
\text { reumatismo e em lavagens externas } \\
\text { indicadas para cicatrização de feridas. }\end{array}$ \\
\hline \multicolumn{4}{|l|}{ URTICACEAE } \\
\hline Urera aurantiaca Wedd. & $\begin{array}{l}\text { urtiga-branca, } \\
\text { urtiguinha }\end{array}$ & 1 & $\begin{array}{l}\text { Utiliza-se as raízes no preparo de chás } \\
\text { diuréticos. }\end{array}$ \\
\hline \multicolumn{4}{|l|}{ VERBENACEAE } \\
\hline $\begin{array}{l}\text { Stachytarpheta cayennensis } \\
\text { (Rich.) Vahl }\end{array}$ & gervão & 1 & $\begin{array}{l}\text { O chá da casca é indicado contra malária, } \\
\text { febre e gripe. }\end{array}$ \\
\hline \multicolumn{4}{|l|}{ ZINGIBERACEAE } \\
\hline Hedychium coronarium J. König & lírio-do-brejo & 2 & $\begin{array}{l}\text { O chá das folhas é empregado, em uso } \\
\text { externo, contra coceiras e micoses. }\end{array}$ \\
\hline
\end{tabular}




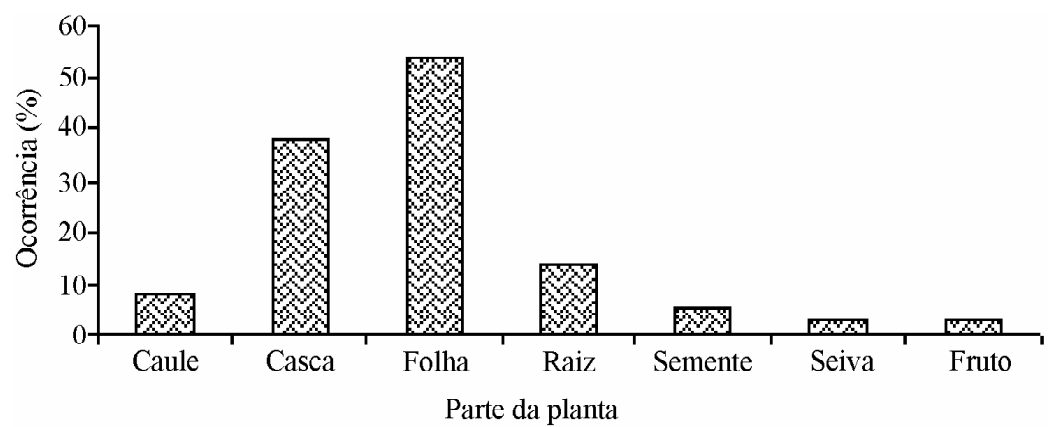

Figura 3 - Parte da planta empregada como uso medicinal pela população de Dourados-MS, nos fragmentos florestais estudados.

Eugenia uniflora L., Psidium guajava L. e Pothomorphe umbellata (L.) Miq. foram descritas no levantamento etnobotânico de plantas com usos terapêuticos no município de Santo Antonio do LevergerMT, realizado por Amorozo (2002).

Guarim Neto \& Morais (2003), realizando uma revisão bibliográfica aprofundada de trabalhos que indiquem as informações das espécies medicinais do cerrado mato-grossense, listaram as seguintes espécies em comum com as encontradas neste estudo: Cecropia pachystachya Trécul, Croton urucurana Baill., Genipa americana L., Guazuma ulmifolia Lam., Pothomorphe umbellata (L.) Miq., Smilax brasiliensis Spreng., Solanum viarum Dun, Trema micrantha (L.) Blume, e Stachytarpheta cayennensis (Rich.) Vahl.

Os resultados deste trabalho despertam a atenção sobre a necessidade da conservação de fragmentos florestais pelo seu potencial na utilização medicinal de suas espécies e ressalta a necessidade da continuidade de estudos vegetacionais no seu aspecto potencial e econômico, além da importância da participação das comunidades no registro de espécies ameaçadas de extinção, pela retirada indiscriminada e predatória de seu habitat de origem.

Considerando os resultados obtidos neste estudo, verifica-se, que nos dois fragmentos florestais, há uma flora rica em espécies de plantas medicinais. A população da região, coleta e utiliza as plantas medicinais para tratamento de diversas enfermidades, sendo que o conhecimento dessas as espécies e formas de utilização é repassada na população de geração para geração. Sendo assim, é importante estudos mais detalhados sobre o potencial dessas plantas, com o intuito de preservação dessas áreas.

\section{REFERÊNCIAS BIBLIOGRÁFICAS}

ALVES SOBRINHO, T.; BONOMO, R.; MANTOVANI, E. C.; SEDIYAMA, G. C. Estimativa mensal da evapotranspiração de referencia para Dourados e Ponta Porã, Mato Grosso do Sul. Cerrados, [S.1.], v. 1, p. 32-34, 1998.

AMOROZO, M. C. M. Uso e diversidade de plantas medicinais em Santo Antonio do Leverger, MT, Brasil. Acta Botanica Brasílica, Porto Alegre, v. 16, n. 21, p. 189-203, 2002.

ANGIOSPERM PHYLOGENY GROUP. An update of the Angiosperm Phylogeny Group classification for the orders and families of flowering plants: APG II. Botanical Journal of the Linnean Society, [S.1.], v. 141, p. 399-436, 2003.

BRATTI, C.; VIEIRA, M. C.; ZÁRATE, N. A. H. Identificação de plantas medicinais nativas da Fazenda Azulão em Dourados-MD. In: ENCONTRO DE INICIAÇÃO CIENTÍFICA, 4., 2004, Campo Grande. Resumos... Campo Grande: PROPP/UFMS, 2004. CD-ROM.

BUENO, N. R.; CASTILHO, R. O.; COSTA, R. B. da; POTT, A.; POTT, V. J.; SCHEIDT, G. N.; BATISTA, M. S. Medicinal plants used by the Kaiowá and Guarani indigenous populations in the Caarapó Reserve, Mato Grosso do Sul, Brazil. Acta Botanica Brasílica, Porto Alegre, v. 19, n. 1, p. 39-44, 2005.

CABALlERO, N. J. Perspectivas para el que hacer etnobotânico en México. In: BARRERA, A. (Ed.). La etnobotânica: tres puntos de vista y una perspectiva. Xalapa: INIREB, 1983.255 p.

ELISABETSKY, E.; SETZER, R. Caboclo concepts of disease, diagnosis, and therapy: implications for ethnofarmacology and health systems in Amazonia. In: PARKER, E. P. (Ed.). The amazon caboclo: historical and contemporany perspectives. Williamsborg: Studies on Third World Societies, 1987. p. 243-278. 
FONSECA-KRUEL, V. S. da; PEIXOTO, A. L. Etnobotânica na reserva extrativista marinha de Arraial do Cabo, RJ, Brasil. Acta Botanica Brasílica, Porto Alegre, v. 18, n. 1, p. 177-190, 2004.

FORTES, C. G.; VIEIRA, M. C.; ZÁRATE, N. A. H. Plantas medicinais em resquícios de mata nativa na Fazenda Paradouro, em Dourados-MS. In: ENCONTRO DE INICIAÇÃO CIENTÍFICA, 4., 2004, Campo Grande. Resumos... Campo Grande: PROPP/UFMS, 2004. CD-ROM.

GUARIM NETO, G.; MORAIS, R. G. de. Recursos medicinais de espécies do cerrado de Mato Grosso: um estudo bibliográfico. Acta Botanica Brasílica, Porto Alegre, v. 17, n. 4, p. 561-584, 2003.

KENT, M.; COKER, P. Vegetation description and analysis: a practical approach. London: Belhaven, 1992. 363 p.

MARQUES, M. B. Patentes farmacêuticas e acessibilidade aos medicamentos no Brasil. História, Ciências, Saúde, Manguinhos, v. 7, n. 1, p. 7-21, 2000.

MING, L. C. Levantamento de plantas medicinais na reserva extrativista "Chico Mendes" - Acre. 1995. 180 f. Tese (Doutorado em Ciências Biológicas) - Universidade Estadual de São Paulo, Botucatu, 1995.

QUEIROZ, M. S. de; VIEIRA, M. C.; ZÁRATE, N. A. H. Coleta e identificação de espécies medicinais nativas na Fazendinha Ecológica, em Dourados - MS, com vegetação característica de cerrado. In: ENCONTRO DE INICIAÇÃO CIENTÍFICA, 6., 2005, Campo Grande. Resumos... Campo Grande: PROPP/UFMS, 2005. CD-ROM.

RAMOS, J. B. Plantas medicinais brasileiras e biopirataria: nossas riquezas em risco. Boletim Aqualung, [S.1.], n. 35,
2000. Disponível em: <http://www.institutoaqualung.com.br/ info_plantas43.html>. Acesso em: 10 out. 2005.

RODRIGUES, V. E. G. Levantamento florístico e etnobotânico de plantas medicinais dos cerrados na região do Alto Rio Grande - Minas Gerais. 1998. 235 f. Dissertação (Mestrado em Engenharia Florestal) - Universidade Federal de Lavras, Lavras, 1998.

SANGALLI, A.; VIEIRA, M. C. Plantas medicinais utilizadas por parte da população de Dourados-MS. Cerrados, [S.1.], v. 6, n. 11, p. 17-20, 2003.

SANGALLI, A.; VIEIRA, M. C.; ZARATE, N. A. H. Levantamento e caracterização de plantas medicinais nativas com propriedades medicinais em fragmentos florestais e de cerrado, em Dourados-MS, numa visão etnobotânica. Acta Horticulturae, The Hague, n. 569, p. 173-184, 2002.

SANTOS, L. F. dos; SCALON, S. P. Q.; VIEIRA, M. C. Levantamento etnobotânico de plantas medicinais em cerrado sentido restrito de Dourados-MS. In: ENCONTRO DE INICIAÇÃO CIENTÍFICA, 2., 2002, Campo Grande. Resumos... Campo Grande: PROPP/UFMS, 2002. p. 42.

SILVA, C. B. da; VIEIRA, M. C.; GOMES, C. A. S.; ZÁRATE, N. A. H. Etnobotânica de plantas medicinais nativas da Fazendinha Ecológica, em Dourados-MS. In: SIMPÓSIO DE PLANTAS MEDICINAIS DO BRASIL, 18., 2004, Manaus. Resumos... Manaus: INPA, 2004. p. 402-403.

SÓ 1,99\% das florestas do país estão protegidas. O Estado de São Paulo, São Paulo, 11 jun. 2000. Ciências, p. A16.

VELOSO, H. P.; RANGEL FILHO, A. L. R.; LIMA, J. C. A. Classificação da vegetação brasileira adaptada a um sistema universal. São Paulo: IBGE, 1991. 123 p. 